\section{Histochemical Localization of Alkaline Phosphatase and Adenosine Triphosphatase in the Myoepithelial Cells of Rat Salivary Glands}

THe histochemical demonstration of alkaline phosphat. ase in the myoepithelial cells of salivary glands, sweat glands and mammary glands has been reported by a number of workers ${ }^{1-7}$.

Leeson ${ }^{5,6}$ distinguishes between the myoepithelial cells surrounding the gland acini which form an extensive, irregularly branching network, and those of the intercalated ducts which are smaller and less extensively ramifying. He points out that the remaining portions of the duct system in rat salivary glands are alkaline phosphatase negative, implying thereby the absence of myoepithelial cells in the large ducts.

My own investigations of the distribution of alkaline phosphatase in rat salivary gland were carried out on fresh-frozen cryostat sections fixed in formol-calcium for 10 min, using naphthol $A S-B I$ phosphate as substrate and coupling with fast red $T R$ (5-chloro-o-toluidine) ${ }^{8}$. The results confirm Leeson's observations with regard to the myoepithelial cells of the acini and intercalated ducts. In addition, however, they clearly indicate the presence of similar cells giving strongly positive reactions for alkaline phosphatase, surrounding the striated ducts (Fig. 1). This suggests that in the rat submaxillary salivary gland, myoepithelial cells are present also in relation to the striated ducts.

Little is known of the function of alkaline phosphatase in myoepithelial cells. Certainly, its demonstration in these cells has contributed little to the understanding of their function. Although Leeson ${ }^{6}$ states that the function of the myoepithelial cells is primarily one of contractility, there is little direct evidence in these cells of metabolic activity normally associated with muscle contraction. Indirect evidence has been provided by the work of Linzell ${ }^{9}$, who found by direct microscopic examination of living mammary glands that the alveoli contracted following stimulation by vasopressin, oxytocin and other agents which produce smooth muscle contraction. A silver impregnation technique was used by Richardson ${ }^{10}$, who observed structural changes in the opithelium of contracted as compared with distended alveoli and ducts in goat mammary glands. More recently, in electron microscope investigations, Scott and Pease ${ }^{11}$ have demonstrated fibrils in the myoepithelial cells of salivary glands which they consider to be evidence that these cells can contract.

The work recorded here was undertaken in order to determine whether adenosine triphosphatase (ATPase), which is known to be present in smooth muscle, is present in the myoepithelial colls of salivary glands. Fresh-

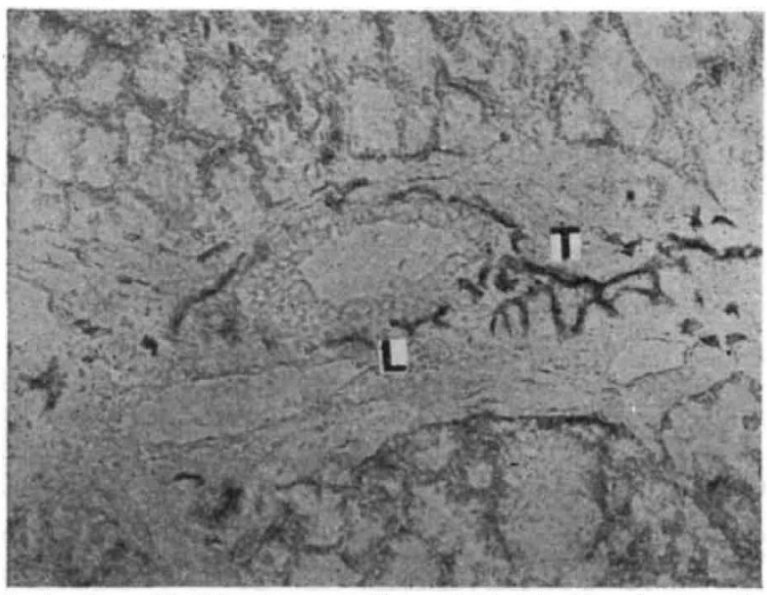

Fig. 1. Myoepithelial cells surrounding a striated duct in rat submaxillary gland. Sectioned longitudinally at $L$ and tangentially at $T$. (Alkaline phosphatase; $\times$ c. 90 )

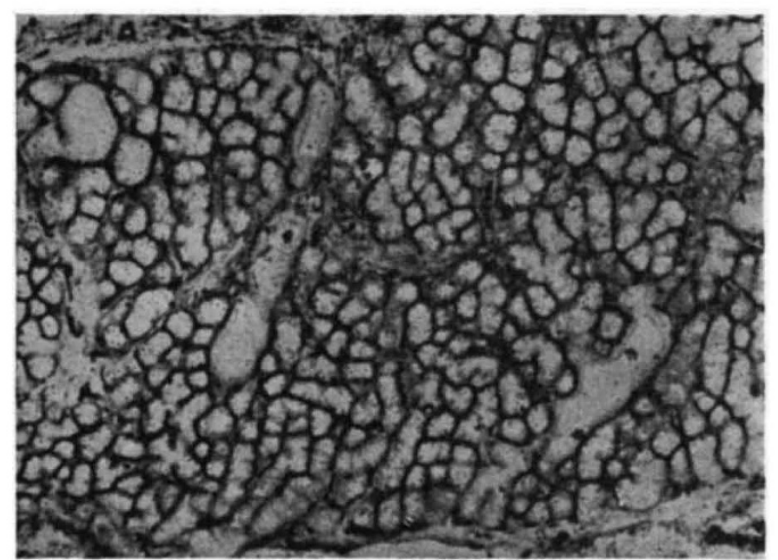

Fig. 2. Myoepithelial cells surrounding mucous acini in rat sublingual gland. (Adenosine triphosphatase; $\times$ c. 45)

frozen cryostat sections were treated either unfixed, or fixed in formol-calcium at $-3^{\circ} \mathrm{C}$ for 5-10 $\mathrm{min}$, and were incubated at $p \mathrm{H} 7 \cdot 2$ for $30 \mathrm{~min}$ at room temperature after the method of Wachstein and $\mathrm{Meisel}^{8}$.

Sections treated in this way show the presence of elongated, flattened cells which give a positive reaction for ATPase surrounding and lying in close contact with the gland acini and ducts. Their distribution is the same as that of the alkaline phosphatase-positive material in rat salivary glands and it may be assumed that they are myoepithelial cells. They form an almost unbroken ring around the mucous acini but are more sparsely located around the striated ducts (Fig. 2). Blood vessels and nerve fibres show equally strong reactions, but the acinar and duct cells themselves show no ATPase activity.

The specificity of the various histochemical reactions for ATPase has frequontly been debated, as non-specific alkaline phosphatase is known to dephosphorylate ATP. The problem is discussed by Pearse ${ }^{8}$, who concludes that, at $p \mathbf{H} 7 \cdot 2$, the $p H$ involved in the Wachstein-Meisel procedure, the activity of non-specific alkaline phosphatase can be ignored. Furthermore, it was noted in this investigation that fixation at room temperature for $15 \mathrm{~min}$ was sufficient to obliterate any activity in these tissues, using the Wachstein-Meisel technique. As similar fixation will obviously not interfere to any marked extent with alkaline phosphatase activity in histochemical procedures, it may be assumed that the enzyme demonstrated here, using the Wachstein--Meisel procedure, is magnesiumactivated ATPase and not non-specific alkalino phosphatase.

The indications are, therefore, that both alkaline phosphatase and ATPase are present in the myoepithelial cells of rat salivary glands. It is suggested that the presence of ATPase in these cells provides further evidence of their contractile nature.

This work was carried out during the tenure of a directed research bursary of the South African Council for Scientific and Industrial Research.

Postgraduate Medical School,

M. SHEAR *

Ducane Road, London, W.12.

* Present address. University of the Witwatersrand, Milner Park, Johannesburg.

1 Bunting, II., et al., Anat. Rec, 100, 61 (1948).

2 Dempsey, E. W., et al., Amer. J. Anat., 81, 309 (1947).

${ }^{3}$ Goldstein, D. J., J. Invest. Derm., 37, 301 (1961).

Holmes, R. L., Nature, 178, 311 (1956).

'Leeson, C. R., Nature, 178, 858 (1956).

- Leeson, C. R., Acta Anat., 40, 87 (1960).

'Silver, I. A., J. Physiol., 125, 8P (1954).

${ }^{8}$ Pearse, A. G. E., Histochemistry: Theoretical and Applied, second ed. (Churchill, London, 1960).

- Linzell, J. L., J. Physiol., 130, 257 (1955).

${ }^{10}$ Richardson, K. C., Proc. Roy. Soc. Lond., B, 136, 30 (1949).

${ }^{11}$ Scott, B. L., and Pease, D. C., Amer. J. Anat., 104, 115 (1959). 